DOI: 10.17805/ggz.2018.2.6

\title{
Экологическое сознание молодежи Москвы
}

\author{
Д. А. Тихомиров
}

Российский экономический университет им. Г. В. Плеханова, г. Москва

Данная статья посвящена экологическому сознанию молодежи Москвы. В ней рассматриваются результаты анкетирования и фокус-группового исследования экологического сознания молодого поколения столичного мегаполиса. Показываются различные аспекты восприятия молодежи экологической ситуации в Москве и ее представления о будущем.

Ключевые слова: экология; экологический кризис; экологическое сознание; экологическое поведение; молодежь; студенть

\section{Ecological Consciousness of Moscow Youth}

D. A. Tikhomirov

Plekhanov Russian University of Economics, Moscow

This article deals with the ecological consciousness of Moscow youth. It discusses the results of a survey and a focus group study of the ecological consciousness of the young generation of Moscow megalopolis. The author shows various aspects of youth's perception of the ecological situation in Moscow and their visions of the future.

Keywords: ecology; environmental crisis; ecological consciousness; ecological behavior; youth; students; Moscow youth; Moscow students

\section{ВВЕДЕНИЕ}

Человечество вступило в XXI век с новыми надеждами. Стремительное научно-технологическое развитие приближает к воплощению давнишнюю мечту о земном бессмертии, переводя эту идею из разряда недостижимого фантастического сюжета в возможный сценарий недалекого будущего (Луков, 2017; Юдин, 2017). Однако весьма радужные перспективы затеняют надвигающиеся новые угрозы, одной из которых является нарастающий экологический кризис. Проблема окружающей среды вошла в современную повестку дня, не случайно 2017 год был объявлен в России Годом экологии. Опросы общественного мнения фиксируют значительное внимание различных социальных групп к экологической проблематике (Тихомиров, Кисткина, 2017а: Электронный ресурс). Обильные разговоры об экологическом кризисе и мрачные сценарии будущего становятся обыденными, затушевывая всю серьезность вопроса и не приводя к переосмыслению социальной реальности. Сложность экологической ситуации заключается в том, что процесс развертывания экологического кризиса носит латентный характер, поэтому различные его проявления практически не ощущаются индивидами в их по- 
вседневной жизни, что затрудняет реальное, а не декларативное осознание этой проблемы. Но и осознание надвигающейся экологической катастрофы вовсе не гарантирует изменение социального поведения индивидов, поскольку оно затрагивает ценностные основы существования в современном обществе потребления (Тихомиров, Кисткина, 2017b).

Тем не менее, понимание проблемы является первым шагом к ее решению, поэтому, прежде чем говорить о корректировке социального поведения индивидов, необходимо проанализировать их экологическое сознание. Именно этой цели и посвящена данная статья, основанная на материалах ряда эмпирических исследований молодежи Москвы, проведенных автором в течение 2017 г.

Методами сбора первичной социологической информации послужили: анкетный опрос (N=100 студентов РЭУ им. Г. В. Плеханова в возрасте 1822 лет, выборка стихийная), онлайн-анкетирование ( $\mathrm{N}=200$ молодых москвичей в возрасте 18-29 лет, выборка стихийная) и фокус-группа (5 по 6 московских студентов в возрасте 18-22 лет в каждой). Выбор объекта исследования в данном случае не случаен, поскольку проблема экологии в основном касается будущего развития, поэтому экологические риски приобретают особую остроту для молодого поколения.

Перейдем к рассмотрению основных результатов исследования.

\section{ПРЕДСТАВЛЕНИЕ МОЛОДЕЖИО \\ ЭКОЛОГИЧЕСКОЙ СИТУАЦИИ В МОСКВЕ}

Большинство (71 \%) молодых москвичей оценивают экологическую обстановку в столице как неблагоприятную (из них скорее неблагоприятной ее считают 48,5 \%), противоположного мнения придерживаются 26,5 \% (из них скорее благоприятной ее считают 22,5 \%) респондентов. Но только 20 \% уверены, что без кардинальных мер по ее улучшению уже не обойтись, тогда как 54 \% опрошенных полагают, что достаточно будет лишь некоторых позитивных изменений. Ощущают наличие экологических проблем в повседневной жизни 59 \% молодых москвичей, из них 42 \% отметили ухудшение экологической ситуации в столичном мегаполисе в последние годы, а 17 \% говорят об ее улучшении. Почти треть (30 \%) опрошенных хотя и предположили наличие экологических проблем в городе, но не видят их влияния на свою жизнь (26 \% женщин и 36 \% мужчин). По 5 \% респондентов отметили отсутствие экологических проблем и интереса к этой теме.

В представлении молодых людей экология стала рассматриваться как важный фактор здоровья человека. Превалирующее большинство молодых москвичей (91 \%) отметили отрицательное воздействие экологической ситуации в мегаполисе на здоровье людей. Следует подчеркнуть, что 61 \% опрошенных пока не ощутили последствий ухудшения экологической ситуации для собственного здоровья, но видят возможные риски в будущем. В этом нет ничего удивительного, поскольку участниками опроса были молодые 
люди. В то же время почти треть (30 \%) опрошенных молодых людей уже связывают экологическую ситуацию со своим здоровьем.

Фокус-групповое исследование также показало, что большинство респондентов ощущают наличие экологических проблем в столичном мегаполисе (в основном выделяя загрязненное состояние воздуха), оценивая экологическую ситуацию как неблагополучную. Определенное влияние на восприятие экологической ситуации в городе оказывает территориальный фактор: студенты, приехавшие в Москву из других российских населенных пунктов, более критично оценивают окружающую среду в столице, нежели москвичи.

Приведем некоторые высказывания респондентов: «Я, когда приезжаю в Москву из Подмосковья, чувствую, что здесь плохо пахнет, сразу ощущается загрязненный воздух, вне Москвы он гораздо лучше» (Андрей, м. 19 лет, г. Москва) (здесь и далее сохраняется авторская редакция. - Д. Т.). «Везде плохо пахнет в самой Москве, вне Москвы гораздо лучше, другой воздух» (Анастасия, ж., 19 лет, г. Подольск, Моск. обл.). «Все очень плохо: загрязнение воздуха, загрязнение улиц» (Алена, ж., 19 лет, г. Чехов, Моск. обл.). «Выхлопные газы, очень тяжело дышать в Москве. Мне гораздо легче дышать в своем городе» (Дарья, ж., 19 лет, г. Чебоксары). «Когда я приезжаю домой из Москвы, у меня часто какая-то утомленность и болит голова от того, что воздух чище, дышать легче. И когда я уезжаю в Москву, здесь снова выхлопные газы, очень много машин, стресс, Москва перегружена» (София, ж., 19 лет, г. Киров). Подчеркнем территориальные различия в восприятии экологии столичного мегаполиса: «Приезжаю из Москвы к себе домой, гораздо легче дышится. Еще много зависит от района: есть более чистые и более грязные районы» (Кирилл, м., 19 лет, г. Липецк). «Ощущается загрязнение в Москве, особенно в центре, в пределах Садового кольца, вне Москвы такого нет» (Рамиль, м., 19 лет, г. Люберцы, Моск. обл.). Но есть и противоположная позиция, которая, правда, высказывалась гораздо реже и в основном мужчинами: «Я не замечаю каких-либо проблем» (Владислав, м., 19 лет, г. Москва). «У меня на Южной (имеется в виду станция метро - прим. ред.) все хорошо, воздух чистый» (Артем, м., 19 лет, г. Владимир).

Большинство молодых людей отмечают негативное влияние экологии города на самочувствие и здоровье. Девушки чаще юношей выражают недовольство качеством воды, видя в ней основную причину проблем с кожей (лица, рук), и состоянием воздуха, что вызывает головные боли. В связи с этим многим комфортнее проводить время загородом, где воздух чище. Кроме того, в городе, по мнению участников опроса, ощущается повышенная усталость, сонливость и спады настроения.

«Я ощущаю влияние экологии на мое здоровье, особенно на волосы и кожу. Кожа становится более сухая» (Дарья, ж., 19 лет, г. Чебоксары). «Болеть стал чаще тут» (Кирилл, м., 19 лет, г. Липецк). «Самочувствие в Москве у меня ухудшается» (Рамиль, м., 19 лет, г. Люберцы, Моск. обл.). «Я ощущаю слабость в своем организме, сонливость, головокружение, все это влияет на мое здоровье, потому что, когда я дышу более свежим воздухом, я чувствую 
себя абсолютно по-другому» (Анастасия, ж., 19 лет, г. Подольск, Моск. обл.). «Я ощущаю на своем здоровье экологию в Москве, из-за экологии у меня ослабленный иммунитет» (София, ж., 19 лет, г. Киров).

Остальные либо не видят особых проблем с экологией и, как следствие, отрицают их влияние на здоровье, либо полагают, что последствия загрязнения окружающей среды могут проявиться в будущем.

«Экология пока не влияет на мое здоровье» (Егор, м., 19 лет, г. Москва). «Никак не ощущается» (Владислав, м., 19 лет, г. Москва). «У меня все нормально, меня все устраивает» (Артем, м., 19 лет, г. Владимир).

Вернемся к рассмотрению результатов анкетирования. Основными факторами загрязнения экологии столицы респонденты считают автомобильный транспорт, промышленные предприятия и мусор. В первую очередь, наибольший вред экологии, по мнению трети (31 \%) опрошенных, наносит автомобильный транспорт и связанные с ним выхлопные газы. Каждый четвертый (24 \%) молодой столичный житель видит угрозу экологии в промышленных предприятиях, а каждый пятый (20 \%) - в загрязнении природы мусором и бытовыми отходами. Вместе с тем почти пятая часть (18 \%) опрошенных основным фактором загрязнения экологической обстановки в Москве считают неэкологичное поведение большинства жителей города, а $7 \%$ связывают ухудшение экологии столицы с нарастающим глобальным экологическим кризисом. Неопределенность в понимании основной угрозы экологии отражается на установках и поведении молодых москвичей. Так, большинство (67 \%) опрошенных не готовы ради улучшения экологии столицы отказаться от использования автомобиля. Не исключают возможность отказа от автомобиля в будущем при условии, если станет удобнее пользоваться общественным транспортом, $16 \%$. И только $4 \%$ респондентов уже приняли решение в пользу окружающей среды.

В сознании молодежи экологическая проблематика пока не достаточно актуализирована. Каждый второй (52\%) опрошенный не интересуется вопросами экологии и состоянием окружающей среды в повседневной жизни, обращая внимание на информацию по этой теме только в случае экстренных происшествий. Эпизодический интерес проявляют 33 \% респондентов и лишь 5,5 \% имеют устойчивый интерес к вопросам экологии. Невысокий интерес к экологической проблематике отражается на оценках респондентов собственного уровня информированности по вопросам экологии мегаполиса. Большинство (62 \%) молодых людей полагают, что они не осведомлены о реальной экологической обстановке в столице. Менее трети (29 \%) опрошенных полагают, что обладают достаточной информацией о состоянии экологической обстановки столицы (из них хорошо осведомленными себя считают только 0,5\%).

Показатели информированности и заинтересованности молодежи экологической ситуацией как важные составляющие экологического сознания находятся на невысоком уровне, что отражается на их социальных установках, представлении и поведении. Молодые люди не осознают вред, наноси- 
мый окружающей среде их образом жизни. Только 15 \% опрошенных признались, что их поведение, так же как и поведение других людей, наносит окружающей среде много вреда. Большинство (57 \%) же молодых людей считают, что их поведение в меньшей степени вредит экологии города по сравнению с другими людьми. Молодежи свойственно снимать с себя ответственность за состояние экологии города, перекладывая ее на других, особенно это характерно для женщин, нежели для мужчин (62 \% против 47 \%). Еще 16 \% респондентов оценивают свое поведение как экологичное.

Поведение, которое респонденты определяют как экологичное, в основном не затрагивает их повседневную жизнь. Для большинства респондентов подобное поведение сводится к выбросу мусора в специально отведенных местах (34\%) и уборке за собой мусора после поездок на природу (36 \%). Незначительное число опрошенных сортируют мусор при выбрасывании (4 \%), сдают опасный мусор в специальные пункты приема (6 \%), отказываются от полиэтиленовых пакетов и ходят в магазин со своим пакетом или тканевой сумкой (3 \%), приобретают экологически чистые продукты (7 \%), участвуют в субботниках и мероприятиях по уборке территории (6 \%), стараются как можно реже пользоваться личным автомобилем (4 \%).

Экологическое поведение молодого поколения пока не включает в себя практики участия в различных экологических проектах. Большинство (77 \%) молодых москвичей не принимают участия в каких-либо экологических акциях, будь то посадка деревьев, уборка парков, лесов и пр. Однако среди них есть и те, кто хотел бы начать участвовать в этих мероприятиях (24 \%). Редко участвуют в них пятая часть (21 \%) респондентов, а регулярно — только 2 \%. Нельзя не отметить наличие серьезного незадействованного ресурса гражданского участия молодежи в экологических акциях. Именно активизация участия этой категории населения должна стать одним из наиболее приоритетных направлений деятельности государства и общественных объединений.

Обеспокоенность экологической ситуацией пока слабо отражается на повседневных практиках молодых москвичей и на их готовности принимать участие в различных экологических проектах. Экологическое сознание в этих аспектах необходимо активизировать, изменяя и установки молодого поколения об ответственности за состояние окружающей среды. Пока же эти представления отличаются высокой неопределенностью. Почти каждый четвертый (24 \%) респондент полагает, что ответственность за экологию города прежде всего должны нести сами люди. Остальные ответы распределились следующим образом: местная власть (города, района) - 17 \%; федеральная власть, правительство в целом - $16 \%$; специальные правительственные службы (Минприроды и т. д.) - 14 \%; предприятия - 12 \%; общественные организации, в том числе экологические - 10 \%; региональная власть (губернатор, глава администрации и региона) - 7 \%.

Восприятие респондентами деятельности органов государственной власти в сфере экологии высвечивает не только негативные оценки, простав- 
ляемые молодыми людьми работе власти в этом направлении, но и явные проблемы информированности населения о реализуемой экологической политике. Всего лишь 2 \% респондентов позитивно оценивают работу власти в этом направлении, 12 \% придерживаются противоположной точки зрения, большинство (73 \%) же молодых людей отметили определенные действия власти, заметив при этом, что этого явно не достаточно. Низкий уровень информированности молодых москвичей об экологической политике столичной власти подтверждается данными опроса, согласно которым только 12 \% респондентов знают о реализации специальных программ по защите природы и улучшению экологии в Москве, 32 \% не имеют о них ни малейшего представления, а 50 \% хотя что-то о них и слышали, но не знают о решаемых ими проблемах.

Оценка респондентов деятельности московской власти носит значительные отличия по ряду направлений. Молодые люди высоко оценивают деятельность власти по благоустройству и озеленению города. Уборкой тротуаров и пешеходных зон удовлетворены 83 \% опрошенных, благоустройством и содержанием парков - 87 \%, уходом и содержанием зеленых насаждений - 70 \%. Гораздо больше нареканий вызывает деятельность власти по контролю качества питьевой воды (не удовлетворены 62 \%) и уровня загрязнения воздуха промышленными предприятиями (не удовлетворены 82 \%).

\section{ПРЕДСТАВЛЕНИЕ МОЛОДЕЖИ ОБ \\ ЭКОЛОГИЧЕСКИХ СЦЕНАРИЯХ БУДУЩЕГО}

В ходе фокус-группового исследования было раскрыто представление студентов о сценариях развития экологической ситуации в будущем. Большинство респондентов полагают, что в недалеком будущем состояние окружающей среды продолжит ухудшаться, оказывая негативное влияние на здоровье человека.

«Ближайшие лет двадцать-тридцать природа будет загрязняться, а дальше, когда качество жизни заметно ухудшится, будут приучать детей с раннего возраста не загрязнять природу» (Рамиль, м., 19 лет, г. Люберцы, Моск. обл.). «Если будет продолжаться все как сейчас, то будет еще хуже, что отразится на здоровье человека» (Владислав, м., 19 лет, г. Москва). «Экология будет изменяться все в худшую сторону. Будет больше онкологических заболеваний» (Дарья, ж., 19 лет, г. Чебоксары). «...которые даже не понятно от чего возникают. Видимо, природа хочет от нас избавиться» (Алена, ж., 19 лет, г. Чехов, Моск. обл.). Особо отметим высказывание одного из респондентов, которое весьма точно обозначает происходящее: «Мне все это напоминает такую картину: человек купается в бассейне, но выливает туда же помои, справляет нужду и в этом купается. Пока каких-то катаклизмов, как, например, наводнений крупных городов, не произойдет, люди не одумаются» (Кирилл, м., 19 лет, г. Липецк).

Но есть и оптимисты, которые считают, что в будущем «ничего страшного не произойдет» (Андрей, м., 19 лет, г. Москва), более того «мы будем 
увеличивать темп восстановления окружающей среды» (Артем, м., 19 лет, г. Владимир) и экологическая ситуация будет становиться «все лучше и лучше, потому что постоянно разрабатываются инновационные проекты по улучшению окружающей среды» (Сусанна, ж., 21 год, г. Москва).

Мнения участников фокус-групп о возможности экологического апокалипсиса разделились примерно поровну. Однако и среди тех, кто допускает негативные сценарии будущего, никто не верит, что в ближайшее столетие могут произойти необратимые изменения в окружающей среде, которые будут угрожать существованию человечества, допуская воплощение мрачных сценариев в отдаленной перспективе.

«Когда качество жизни сильно ухудшится и будут чувствоваться заметные изменения экологии, люди не будут сидеть сложа руки, начнут чистить заводы и так далее» (Рамиль, м., 19 лет, г. Люберцы, Моск. обл.). «Человек будет приспосабливаться до последнего» (Анастасия, ж., 19 лет, г. Подольск, Моск. обл.). «Если дойдет до пика проблемы, то человечество что-то предпримет, какие-то жесткие меры. А на человеке это отразится напрямую, так как все взаимосвязано в мире, человек будет страдать» (София, ж., 19 лет, г. Киров). «Если что-то и произойдет, то не в ближайшие лет сто» (Владислав, м., 19 лет, г. Москва).

Определяющая роль в решении экологической проблемы отводится технологическому прогрессу. «В дальнейшем экология будет ухудшаться, люди будут стараться приспосабливаться, разрабатывая различные технологии, жизнь человека непременно будет становиться более сложной в техническом плане» (Эдуард, м., 21 год, г. Москва). «Экология ухудшится, но на здоровье граждан это не отразится, благодаря будущим новейшим технологиям» (Максим, м., 21 год, г. Москва). «В будущем будут исчерпаны природные ресурсы, что побудит человека к их замещению или же к оптимизации их использования, чтобы улучшить ситуацию. Думаю, что человечество всегда найдет выход, особенно если вопрос касается его комфорта. Наука не стоит на месте, поэтому будут найдены пути для повышения здоровья, для производства и выращивания продуктов питания» (Дарья, ж., 21 год, г. Москва).

Надежда на экологическое восстановление связывается с Западом. «В развитых западных странах тенденция к улучшению экологической обстановки набирает обороты. Со временем в них все сведется к минимизации влияния на экологию. Из этих стран отношение к окружающей среде распространится на соседние территории» (Никита, м., 22 года, г. Москва).

Молодые люди выделяют разнообразные меры решения экологической проблемы, акцентируя ответственность за сохранение окружающей среды не только власти, но и индивидов.

«Каждому человеку надо элементарно мусор доносить до урны, а власти необходимо ввести большие штрафы» (Дмитрий, м., 19 лет, г. Реутов, Моск. обл.). «Необходим всеобъемлющий, системный подход к решению этой проблемы» (Алена, ж., 19 лет, г. Чехов, Моск. обл.). «Решение экологи- 
ческого кризиса требует очень масштабной работы, надо в первую очередь заниматься сортировкой мусора, строить новые очистительные сооружения» (Дарья, ж., 19 лет, г. Чебоксары). Трудно не согласится с одним из респондентов, выразившим в весьма изысканном художественном стиле определяющее значение в решении проблемы окружающей среды формирования экологического сознания: «Можно назвать кучу мер экологических: высаживать деревья, выносит мусор, но все это невозможно без осознания того, что человек является частью природы от рождения, что он полностью зависит от природы. Может, слишком пафосно звучит, но природа - его мать, а убивать свою мать невозможно и нельзя» (Кирилл, м., 19 лет, г. Липецк).

\section{ЗАКЛЮЧЕНИЕ}

Исследование экологического сознания молодежи Москвы показало, что молодые люди хотя и обеспокоены проблемой окружающей среды, но не верят в экологический апокалипсис в обозримом будущем. Надежда на улучшение экологической ситуации связывается не с изменением мышления и поведения индивидов, а с технологическим прогрессом. Менять свой образ жизни юноши и девушки не намерены еще и потому, что не наблюдают за собой неэкологичного поведения, перенося всю ответственность за загрязнение природы на других, отводя решающую роль в решении проблемы окружающей среды различным органам власти. В итоге экологическая проблематика пока не вошла в повседневную жизнь молодежи, что отражается в их социальных практиках.

\section{СПИСОК ЛИТЕРАТУРЫ}

Луков, В. А. (2017) Иммортализм в свете тезаурусного подхода // Биотехнологическое улучшение человека как проблема социальногуманитарного знания : материалы Школы молодых ученых / под ред. Б. Г. Юдина, О. В. Поповой. М. : Изд-во Моск. гуманит. ун-та. 208 с. С. 120127.

Тихомиров, Д. А., Кисткина, И. А. (2017а) Проблема осознания экологической угрозы в России [Электронный ресурс] // Горизонты гуманитарного знания. № 2. С. 55-61. URL: http://journals.mosgu.ru/ggz/article/view/ 462 (дата обращения: 26.02.2018). DOI: 10.17805/ggz.2017.2.5

Тихомиров, Д. А., Кисткина, И. А. (2017b) Экология и социальные практики современной цивилизации // Социальная антропология: интеграция наук : сб. науч. ст. по итогам Международной научной конференции, г. Москва, 12 октября 2017 г. М. : Изд-во РЭУ им. Г. В. Плеханова. 248 с. С. 189-192.

Юдин, Б. Г. (2017) Гуманитарный анализ биотехнологических проектов «улучшения» человека: философские основания // Биотехнологическое улучшение человека как проблема социально-гуманитарного знания : материалы Школы молодых ученых / под ред. Б. Г. Юдина, О. В. Поповой. М. : Изд-во Моск. гуманит. ун-та. 208 с. С. 5-9. 
Дата поступления: 11.03.2018 2.

Тихомиров Дмитрий Андреевич — кандидат социологических наук, доцент кафедры политологии и социологии РЭУ им. Г. В. Плеханова. Адрес: 117997, Москва, Стремянный пер., 28, корп. 1. Тел.: +7 (495) 958-23-27. Эл. адрес: dat1983@yandex.ru

Tikhomirov Dmitry Andreevich, Candidate of Sociology, Associate Professor, Department of Political Science and Sociology, Plekhanov Russian University of Economics. Postal address: Bldg. 128, Stremyannyi Lane, 117997 Moscow, Russian Federation. Tel.: +7 (495) 958-23-27. E-mail: dat1983@yandex.ru

\section{Для ичитирования:}

Тихомиров Д. А. Экологическое сознание молодежи Москвы [Электронный ресурс] // Горизонты гуманитарного знания. 2018. № 2. С. 65-73. URL: http://journals.mosgu.ru/ggz/article/view/762 (дата обращения: дд.мм.гг гг). DOI: 10.17805/ggz.2018.2.6 